\title{
Elderly patients with no previous psychiatric history: suicidality and other factors relating to psychiatric acute admissions
}

Hallvard Lund-Heimark, Eirik Kjelby, Lars Mehlum, Rolf Gjestad, Geir Selbæk, Rune Andreas Kroken, Erik Johnsen, Ketil Joachim Oedegaard and Liv S. Mellesdal

\section{Background}

The common recommendation that adults with onset of mental illness after the age of 65 should receive specialised psychogeriatric treatment is based on limited evidence.

\section{Aims}

To compare factors related to psychiatric acute admission in older adults who have no previous psychiatric history (NPH) with that of those who have a previous psychiatric history (PPH).

\section{Method}

Cross-sectional cohort study of 918 patients aged $\geq 65$ years consecutively admitted to a general adult psychiatric acute unit from 2005 to 2014

\section{Results}

Patients in the NPH group $(n=526)$ were significantly older than those in the PPH group $(n=391)(77.6$ v. 70.9 years $P<0.001)$ more likely to be men, married or widowed and admitted involuntarily. Diagnostic prevalence in the NPH and PPH groups were $49.0 \%$ V. $8.4 \%(P<0.001)$ for organic mental disorders, $14.6 \%$ V. $30.4 \%(P<0.001)$ for psychotic disorders, $30.2 \%$ v. $55.5 \%(P<$ $0.001)$ for affective disorders and $20.7 \%$ V. 13.3\% ( $P=0.003)$ for somatic disorders. The NPH group scored significantly higher on the Health of the Nation Outcome Scale (HoNOS) items agitated behaviour; cognitive problems; physical illness or disability and problems with activities of daily living, whereas those in the PPH group scored significantly higher on depressed mood. Although the PPH group were more likely to report suicidal ideation, those in the NPH group were more likely to have made a suicide attempt before the admission.

\section{Conclusions}

Among psychiatric patients $>65$ years, the subgroup with NPH were characterised by more physical frailty, somatic comorbidity and functional and cognitive impairment as well as higher rates of preadmission suicide attempts. Admitting facilities should be appropriately suited to manage their needs.

\section{Keywords}

Geriatric psychiatry; acute admissions; hospitalisations; first admission; suicidality.

\section{Copyright and usage}

(c) The Author(s) 2020. Published by Cambridge University Press on behalf of the Royal College of Psychiatrists. This is an Open Access article, distributed under the terms of the Creative Commons Attribution-NonCommercial-NoDerivatives licence (http://creativecommons.org/licenses/by-nc-nd/4.0/), which permits non-commercial re-use, distribution, and reproduction in any medium, provided the original work is unaltered and is properly cited. The written permission of Cambridge University Press must be obtained for commercial re-use or in order to create a derivative work.

\section{Background}

Older adults in need of psychiatric treatment differ from younger ones with higher rates of suicide, ${ }^{1}$ somatic comorbidity, physical frailty, cognitive and functional decline, symptom presentation and pharmacokinetic characteristics. ${ }^{2-5}$ Most current guidelines recommend specialised psychogeriatric treatment when mental illness starts after the age of $65 .^{6-9}$ Consequently, older adults are often treated within general adult psychiatry if they have a previously established mental disorder with few age-related complications, ${ }^{8}$ if they are formerly known to service providers ${ }^{7}$ or if preferred by the patient. ${ }^{10}$ Although psychogeriatric units have been shown to be superior to general adult psychiatry at providing a comprehensive medical and psychiatric work-up ${ }^{11}$ and at meeting the needs of elderly patients, ${ }^{12}$ there is no clear international consensus concerning the subdivision in general adult or psychogeriatric services - which is based on expert opinion rather than clinical evidence.

The proposal in a guideline in the UK by the Royal College of Psychiatrists, omitting the original age-based World Health Organization definition and instead further emphasising the patient's need and choice, ${ }^{10}$ was also primarily motivated by political decisions rather than the emergence of new evidence. ${ }^{13}$ Against this backdrop, several guidelines emphasise the need for further research. ${ }^{7,8,14}$

In the very few studies specifically investigating the characteristics of older adults with mental illness presenting in later life the most robust finding is the association between first admissions and organic psychiatric disorders. ${ }^{15-17}$ In in-patients with depression, a link between first admissions and increased suicide risk has been reported. ${ }^{18}$ However, the mentioned studies show significant heterogeneity with regard to sample sizes, setting, age cut-off and methodological quality. Information about first admission and/or previous psychiatric history $(\mathrm{PPH})$ is usually only mentioned briefly. The only prior study conducting subgroup analyses based on psychiatric history reported that patients with no previous psychiatric history $(\mathrm{NPH})$ were more likely than elderly patients with PPH to have concurrent medical and cognitive problems and less likely to have bipolar or psychotic disorders. ${ }^{17}$ However, this study was set in a general hospital emergency room, employed an age cut-off of 60 and the sample size was small.

\section{Study objectives}

In Norway, despite national guidelines recommending psychogeriatric treatment for patients with mental illness presenting at $\geq 65$ years, ${ }^{8}$ older adults in need of acute hospital admission are initially admitted to general adult psychiatric acute units (PAUs) - however, knowledge about these patients is scarce. As research suggests that psychogeriatric units are superior to general adult psychiatric units at providing a comprehensive assessment and treatment to complex geriatric patients ${ }^{11,12}$ it may be assumed that central guideline criteria would allocate the patients most in need to this service. Thus, patients with NPH should be more likely than elderly patients 
with PPH to present with more physical frailty, somatic comorbidity and impaired everyday functioning, also in the general adult acute psychiatric setting. However, evidence to support this hypothesis is scarce. In order to provide a stronger empirical basis for how to organise mental health services for elderly people, further investigation of psychiatric admissions of older adults, especially those with mental illness presenting at $\geq 65$ years, is needed. The main objective of our study was, in a cohort of older adults admitted to a PAU, to examine differences between patients with NPH and patients with PPH.

\section{Method}

\section{Setting and study population}

All data was retrieved from the cohort study Suicidality in Psychiatric Emergency Admissions (SIPEA), which includes all admissions to the PAU at Haukeland University Hospital in Bergen, Norway, from May 2005 to July 2014. ${ }^{19,20}$ The Norwegian state provides free universal healthcare with virtually no competition from the private sector, and the PAU received 95\% of all acute psychiatric admissions from a catchment area of approximately 350000 people aged $\geq 18$ years. A total of 7000 patients were admitted to the PAU during the study period. The present study included a subsample consisting of all patients aged $\geq 65$ years at the time of admission $(n=918 ; 13.1 \%$ of the total patient population) (Fig. 1). Based on the patient records, we separated patients into two groups: patients with either psychiatric admissions or follow-up from a psychiatrist, psychologist or a psychiatric outpatient clinic before the age of 65 were defined as having PPH (the PPH group, $n=391$ ), whereas those whose psychiatric specialist follow-up started after the age of 65 or who had no known psychiatric history before their admission(s) at the PAU were defined as having NPH (the NPH group, $n=526$ ). One patient was excluded from the analyses as information regarding previous psychiatric follow-up was unavailable.

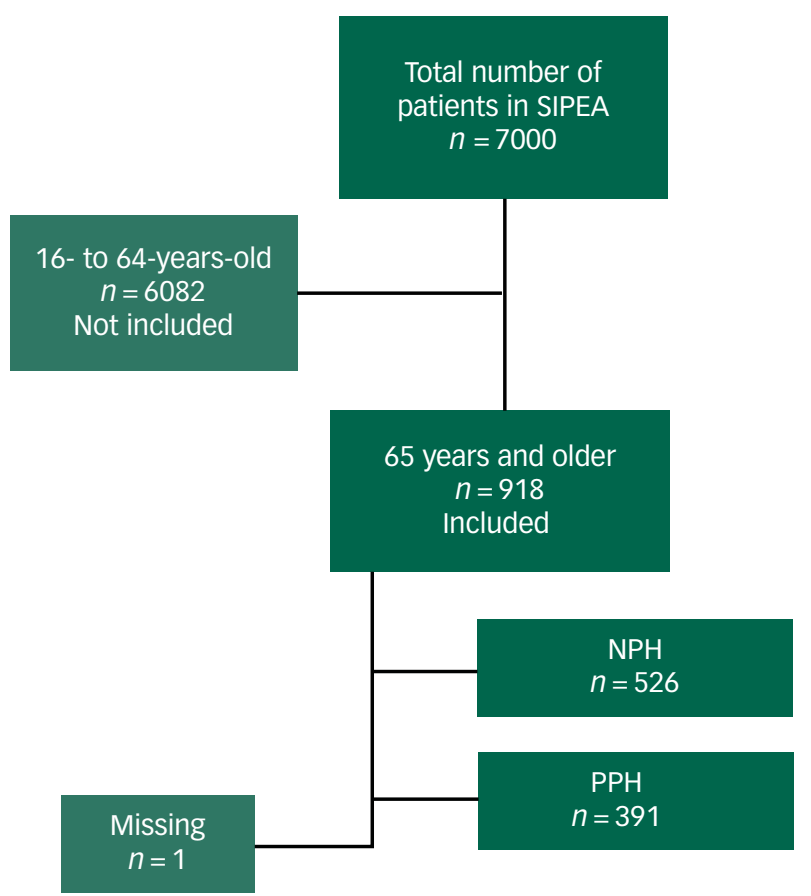

Fig. 1 Patient flow chart.

$\mathrm{NPH}$, no previous psychiatric history; PPH, no previous psychiatric history; SIPEA, Suicidality in Psychiatric Emergency Admissions.

\section{Measurements}

Demographic patient information and information concerning the use of coercion (involuntary medical treatment and seclusion) during the admission was extracted from the patient files by research nurses. Length of stay at the PAU and total psychiatric hospital stay was calculated as well as information about discharge/ transfer to other units (general adult psychiatry, psychogeriatric or somatic) and to nursing homes.

Information on the legal formality of the admission included: (a) involuntary referral/admission to psychiatric assessment at the PAU under the Norwegian Mental Health Act and (b) the decision about involuntary commitment (or not) by a specialist in psychiatry or clinical psychology within $24 \mathrm{~h}$ of admission to the PAU.

Patients were assessed at the time of admission by the psychiatric resident on-call as to whether suicidality was the reason for admission or not (yes/no). Details on suicidality were coded as (a) no known suicide ideation, (b) suicide ideation, (c) non-suicidal self-harm, (d) suicide attempt, and (e) unknown.

Alcohol and drug use was recorded using the Clinician's Alcohol/Drug Use Scales ${ }^{21}$ and results dichotomised to 'no abuse' (scores 1-2) and 'abuse' (scores 3-5). Data regarding aggressive behaviour, symptoms and functioning in the 2 weeks preceding admission was collected using the data from Health of the Nation Outcome scales (HoNOS), ${ }^{22}$ which was scored at admission. HoNOS is a rating tool developed to measure the health and social functioning of people with severe mental illness and comprises 12 items (see Table 2) that are all scored from zero (no problem) to four (severe to very severe problem).

At admission, functioning in daily life was assessed by the General Assessment of Functioning (GAF) - split version: GAF is a numeric scale ranging from zero through 100 that is used to subjectively rate the social, occupational and psychological functioning of adults. ${ }^{23,24}$ The split version assesses the patient's level of symptoms (GAF-S) and functioning (GAF-F), respectively.

Clinical diagnoses assigned by clinicians in the PAU according to the ICD- $10^{25}$ were grouped into categories based on ICD-10 subchapters: organic, including symptomatic, mental disorders (F00-F09), schizophrenia, schizotypal and delusional disorders (F20-F29), affective disorders (F30-F39) and neurotic, stress-related and somatoform disorders (F40-F49). The remaining diagnostic categories from the Fchapter were subgrouped as 'other psychiatric diagnoses', and diagnoses from the somatic chapters of ICD-10 were clustered into 'somatic diagnoses'. Up to three diagnoses were registered at discharge. The diagnoses were scored as 1 (present) when given as the main diagnosis or one of the secondary diagnoses, otherwise as 0 (not present).

Drugs acting on the nervous system, i.e. drugs from the Nchapter of the Anatomical Therapeutic Chemical (ATC) classification system were registered at admission for each patient.

\section{Statistical analyses}

IBM $^{\circledR}$ SPSS $^{\star}$ Statistics version 24 was used for the statistical analyses. Subgroup analyses were performed using Pearson $\chi^{2}$-test for nominal dichotomous variables and Wilcoxon-Mann-Whitney non-parametric test for continuous variables. Statistical significance level was set at $P=0.05$. In order to adjust for the age difference between the groups, sensitivity analyses were conducted analysing statistically significant results sequentially using logistic regression for dichotomous variables and linear regression for continuous variables. These analyses were then repeated after patients with organic mental disorders were excluded, since organic disorders were disproportionately frequent in the NPH group. For patients with multiple admissions, data from the first admission after turning 65 years was used. Multiple imputation was used to impute values when information for HoNOS variables were missing. ${ }^{26}$ This method draws 
Table 1 Demographic and clinical characteristics differences for patients aged 65 years or older admitted to the psychiatric acute unit (PAU)

\begin{tabular}{|c|c|c|c|c|c|}
\hline & $\begin{array}{c}\text { NPH } \\
(n=526)^{\mathrm{a}}\end{array}$ & $\begin{array}{c}\text { PPH } \\
(n=391)^{\mathrm{a}}\end{array}$ & $\begin{array}{c}\text { Total } \\
(n=917)^{\mathrm{a}}\end{array}$ & $\chi^{2}$ & $P$ \\
\hline Age, years; mean (s.d.) & $77.6(7.87)$ & $70.9(5.97)$ & 74.7 (7.84) & - & $<0.001$ \\
\hline Length of stay in PAU, days; mean (s.d.) & $3.8(3.77)$ & $3.4(3.55)$ & $3.6(3.68)$ & - & 0.091 \\
\hline GAF symptoms score, mean (s.d.) & $32.9(12.3)$ & $37.3(11.6)$ & $34.8(12.2)$ & - & $<0.001$ \\
\hline GAF function score, mean (s.d.) & $34.3(14.5)$ & $37.5(11.8)$ & $35.6(13.4)$ & - & $<0.001$ \\
\hline Women, $n(\%)$ & $260(49.4)$ & $249(63.7)$ & $509(55.5)$ & 18.449 & $<0.001$ \\
\hline Living alone, $n(\%)$ & $261 / 520(50.2)$ & $241 / 383(62.9)$ & $502 / 903(55.6)$ & 14.482 & $<0.001$ \\
\hline \multicolumn{6}{|l|}{ Marital status, $n(\%)$} \\
\hline Married/partner & 218/521 (41.8) & 117/390 (30.0) & 335/911 (36.8) & 13.454 & $<0.001$ \\
\hline Widowed & $154 / 521(29.6)$ & 71/390 (18.2) & $225 / 911(24.7)$ & 15.458 & $<0.001$ \\
\hline Separated/divorced & 76/521 (14.6) & 93/390 (23.8) & 169/911 (18.6) & 12.654 & $<0.001$ \\
\hline Single & $65 / 521(12.5)$ & 107/390 (27.4) & $172 / 911(18.9)$ & 32.592 & $<0.001$ \\
\hline \multicolumn{6}{|l|}{ Living arrangement, $n$ (\%) } \\
\hline House/apartment & 405/524 (77.3) & $328 / 390(84.1)$ & 733/914 (80.2) & 6.642 & 0.010 \\
\hline Living in an institution & 62/524 (11.8) & 20/390 (5.1) & 82/914 (9.0) & 12.304 & $<0.001$ \\
\hline \multicolumn{6}{|l|}{ Abuse/addiction, $n$ (\%) } \\
\hline Alcohol & $50 / 478(10.5)$ & 29/361 (8.0) & 79/839 (9.4) & 1.420 & 0.233 \\
\hline Drugs & $7 / 478$ (1.5) & 10/353 (2.8) & $17 / 831(2.0)$ & 1.897 & 0.168 \\
\hline \multicolumn{6}{|l|}{ Admission formalities, $n$ (\%) } \\
\hline Involuntary referral & $370(70.3)$ & $219(56.0)$ & $589(64.2)$ & 20.052 & $<0.001$ \\
\hline Involuntary commitment & $272(51.7)$ & $173(44.2)$ & $445(48.5)$ & 5.004 & 0.025 \\
\hline \multicolumn{6}{|l|}{ Suicide risk, $n$ (\%) } \\
\hline As reason for admission & 158/523 (30.2) & 128/383 (33.4) & 286/906 (31.6) & 1.055 & 0.304 \\
\hline Suicidal ideation & $135 / 510(26.5)$ & 131/373 (35.1) & 266/883 (30.1) & 7.658 & 0.006 \\
\hline Non-suicidal self-harm & $21 / 510(4.1)$ & 16/373 (4.3) & $37 / 883$ (4.2) & 0.016 & 0.900 \\
\hline Suicide attempt & $32 / 510(6.3)$ & 8/373 (2.1) & $40 / 883(4.5)$ & 8.496 & 0.004 \\
\hline \multicolumn{6}{|l|}{ Use of coercion in PAU, $n$ (\%) } \\
\hline Involuntary medication & $11(2.1)$ & $11(2.8)$ & $22(2.4)$ & 0.499 & 0.480 \\
\hline Seclusion & $13(2.5)$ & $17(4.3)$ & $30(3.3)$ & 2.495 & 0.114 \\
\hline \multicolumn{6}{|l|}{ Diagnoses, $n(\%)$} \\
\hline Organic mental disorders & $258(49.0)$ & $33(8.4)$ & $291(31.7)$ & 170.734 & $<0.001$ \\
\hline Psychotic disorders & $77(14.6)$ & $119(30.4)$ & $196(21.4)$ & 33.299 & $<0.001$ \\
\hline Affective disorders & $159(30.2)$ & $217(55.5)$ & $376(41.0)$ & 59.208 & $<0.001$ \\
\hline Neurotic disorders & $55(10.5)$ & $42(10.7)$ & $97(10.6)$ & 0.019 & 0.889 \\
\hline Somatic disorders & $109(20.7)$ & $52(13.3)$ & $161(17.6)$ & 8.538 & 0.003 \\
\hline \multicolumn{6}{|l|}{ Discharge/transfer from PAU, $n$ (\%) } \\
\hline General psychiatric unit & $131(24.9)$ & $238(60.9)$ & $369(40.2)$ & 120.636 & $<0.001$ \\
\hline Psychogeriatric unit & $232(44.1)$ & 78 (19.9) & $310(33.8)$ & 58.491 & $<0.001$ \\
\hline Somatic hospital & 55 (10.5) & $18(4.6)$ & $73(8.0)$ & 10.485 & 0.001 \\
\hline Nursing home & $29(5.5)$ & $5(1.3)$ & $34(3.7)$ & 11.264 & 0.001 \\
\hline Home/other & 79 (15.0) & $52(13.3)$ & $131(14.3)$ & 0.227 & 0.633 \\
\hline
\end{tabular}

plausible values from a conditional distribution based on the mean and covariance structure between all variables. Multiple imputation is recommended even if missingness to some degree deviates from the missing at random assumption. ${ }^{27}$ Integer values were used in order to keep the variable at ordinal level.

\section{Ethics}

The study was approved by the Regional Committee for Medical Research Ethics and the Norwegian Social Science Data Service. The Norwegian Directorate of Health gave permission to use patient information.

\section{Results}

\section{Patient characteristics}

A total of 917 patients, mean age 74.7 years (s.d. $=7.8$ ) and $55.5 \%$ of women were included (Table 1). Compared with the PPH group, the NPH group were significantly older $(P<0.001)$ and a higher proportion were men $(P<0.001)$. More of the NPH group were married/in a partnership or widowed, whereas those in the PPH group were more likely to be single, divorced or living alone at the time of admission $(P<0.001$ for all).

\section{Admission formalities, discharge and transfer to other units}

A higher proportion of the NPH group than the $\mathrm{PPH}$ group were referred/admitted involuntarily to the PAU $(P<0.001)$. In total, length of stay in the PAU before discharge/transfer to other units was 3.6 days (s.d. $=3.7$ ). The NPH group were most likely to be transferred to psychogeriatric units, whereas most of the $\mathrm{PPH}$ group were transferred to general adult psychiatric units $(P<$ 0.001 for both) (Table 1). In addition to the 310 patients transferred directly from the PAU to a psychogeriatric unit, a further 51 patients were transferred to a psychogeriatric unit after receiving initial treatment at a general adult psychiatric unit.

\section{Suicidality}

In total, $31.6 \%$ of admissions were because of suicide risk. Although the $\mathrm{PPH}$ group were more likely to report suicidal ideation $(P=0.006)$, the NPH group were more likely to have made a suicide attempt before the admission $(P=0.004)$ (Table 1). 
Table 2 Differences in Health of the Nation Outcome Scale (HoNOS) scores for patients aged 65 years or older admitted to the psychiatric acute unit by group

\begin{tabular}{|c|c|c|c|c|c|}
\hline HoNOS item ${ }^{a}$ & $\begin{array}{l}\text { NPH, mean (s.d.) } \\
\quad(n=526)\end{array}$ & $\begin{array}{l}\text { PPH, mean (s.d.) } \\
\quad(n=391)\end{array}$ & $\begin{array}{l}\text { Total, mean (s.d.) } \\
\qquad(n=917)\end{array}$ & $Z^{\mathrm{b}}$ & $P$ \\
\hline 1. Aggressive behaviour & $1.21(1.26)$ & $0.78(0.96)$ & $1.03(1.16)$ & -4.839 & $<0.001$ \\
\hline 2. Self-harm & $0.54(1.11)$ & $0.50(0.95)$ & $0.52(1.04)$ & -0.635 & 0.526 \\
\hline 3. Drug and alcohol use & $0.38(0.87)$ & $0.36(0.88)$ & $0.37(0.88)$ & -0.364 & 0.716 \\
\hline 4. Cognitive problems & $1.87(1.37)$ & $0.98(1.02)$ & $1.50(1.31)$ & -9.768 & $<0.001$ \\
\hline 5. Physical illness and disability & $1.40(1.14)$ & $1.18(1.09)$ & $1.31(1.12)$ & -2.798 & 0.005 \\
\hline 6. Hallucinations and delusions & $1.62(1.38)$ & $1.45(1.37)$ & $1.55(1.38)$ & -1.829 & 0.067 \\
\hline 7. Depression & $1.34(1.24)$ & $1.52(1.27)$ & $1.41(1.25)$ & -2.142 & 0.032 \\
\hline 9. Relationships & $1.51(1.17)$ & $1.51(1.08)$ & $1.51(1.13)$ & -0.228 & 0.819 \\
\hline 10. Activities of daily living & $1.84(1.20)$ & $1.54(1.08)$ & $1.71(1.16)$ & -3.790 & $<0.001$ \\
\hline 11. Residential environment & $0.78(1.06)$ & $0.68(0.97)$ & $0.74(1.02)$ & -1.433 & 0.152 \\
\hline 12. Daytime activities & $0.84(1.07)$ & $0.94(1.14)$ & $0.88(1.10)$ & -1.370 & 0.171 \\
\hline
\end{tabular}

\section{Diagnoses, symptoms and functional assessment}

A higher proportion of the NPH group were diagnosed with organic mental disorders $(P<0.001)$ and somatic disorders $(P=0.003)$, whereas affective and psychotic disorders were more common in the PPH group $(P<0.001$ for both) (Table 1). Mean GAF scores were lower in the NPH than the PPH group for both symptoms (GAF-S) and functioning (GAF-F) $(P<0.001$ for both). Alcohol and drug abuse/addiction was present in about $10 \%$ and $2 \%$ of the patients, respectively, with no differences between the NPH and $\mathrm{PPH}$ groups. The NPH group scored higher than the PPH group on the HoNOS items agitated behaviour; cognitive problems; problems with activities of daily living $(\mathrm{P}<0.001$ for all $)$ and physical illness or disability $(P=0.005)$. The $\mathrm{PPH}$ group scored higher on the item depressed mood $(P=0.032)$ (Table 2$)$.

\section{Psychotropic medication}

At admission, the mean number of psychotropic drugs was 1.27 (s.d. =1.3) in the NPH group and 1.8 (s.d.=1.45) in the PPH group $(P<0.001)$. A higher proportion of the NPH group had prescriptions for anti-dementia drugs $(P<0.001)$, whereas a higher proportion of the $\mathrm{PPH}$ group had prescriptions for mood stabilisers $(P<0.001)$, antipsychotics $(P<0.001)$ and benzodiazepines $(P=0.027)$ (Table 3).

\section{Adjusting for age differences and organic disorder diagnosis}

After adjusting for age difference the majority of subgroup differences remained statistically significant, including psychiatric diagnoses, suicide attempts, involuntary admissions, use of psychotropic medication, problems with aggression, cognitive impairment, severity of psychiatric symptoms (GAF-S) and psychiatric discharge/transfer destination (supplementary Tables 1 and 2 available at https://doi.org/10.1192/bjo.2020.45). Variables that did not remain statistically significant included suicide ideation, functional impairment and disability, severity of depression, somatic comorbidity and transfer to a general hospital.

Repeating the age-controlled analyses after excluding patients with organic mental disorder, subgroup differences that were robust for these sensitivity analyses were most of the sociodemographic and discharge characteristics, diagnosis within psychotic disorders and suicide attempts. Variables that did not remain statistically significant included involuntary admissions, discharge to nursing home, problems with aggression, cognitive impairment

\begin{tabular}{|c|c|c|c|c|c|}
\hline & $\begin{array}{c}\text { NPH, } \\
n(\%) \\
(n=526)\end{array}$ & $\begin{array}{c}\text { PPH, } \\
n(\%) \\
(n=391)\end{array}$ & $\begin{array}{c}\text { Total, } \\
n(\%) \\
(n=917)\end{array}$ & $\chi^{2}$ & $P$ \\
\hline Opioids & $18(3.4)$ & $5(1.3)$ & $23(2.5)$ & 4.213 & 0.040 \\
\hline Mood stabilisers & $25(4.8)$ & $81(20.7)$ & $106(11.6)$ & 55.905 & $<0.001$ \\
\hline Lithium & $5(1.0)$ & $34(8.7)$ & $39(4.3)$ & 33.039 & $<0.001$ \\
\hline Antiepileptics & $20(3.8)$ & $54(13.8)$ & $74(8.1)$ & 30.284 & $<0.001$ \\
\hline Antiparkinsonian & $5(1.0)$ & $14(3.6)$ & $19(2.1)$ & 7.646 & 0.006 \\
\hline Antipsychotics & $156(29.7)$ & $175(44.8)$ & $331(36.1)$ & 22.167 & $<0.001$ \\
\hline First generation & $66(12.5)$ & $67(17.1)$ & $133(14.5)$ & 3.807 & 0.051 \\
\hline Second generation & 96 (18.3) & $128(32.7)$ & $224(24.4)$ & 25.493 & $<0.001$ \\
\hline Benzodiazepines & 89 (16.9) & 89 (22.8) & $178(19.4)$ & 4.893 & 0.027 \\
\hline Z-hypnotics & $77(14.6)$ & $62(15.9)$ & $139(15.2)$ & 0.259 & 0.611 \\
\hline Antidepressants & $179(34.0)$ & $151(38.6)$ & $330(36.0)$ & 2.050 & 0.152 \\
\hline Tricyclic & $10(1.9)$ & $16(4.1)$ & $26(2.8)$ & 3.908 & 0.048 \\
\hline $\begin{array}{l}\text { Selective serotonin } \\
\text { reuptake inhibitor }\end{array}$ & $100(19.0)$ & $88(22.5)$ & $188(20.5)$ & 1.681 & 0.195 \\
\hline $\begin{array}{l}\text { Other } \\
\text { antidepressants }\end{array}$ & $104(19.8)$ & $81(20.7)$ & $185(20.2)$ & 0.124 & 0.725 \\
\hline Anti-dementia drugs & $32(6.1)$ & $2(0.5)$ & $34(3.7)$ & 19.505 & $<0.001$ \\
\hline Other drugs & $25(4.8)$ & $23(5.9)$ & $48(5.2)$ & 0.577 & 0.448 \\
\hline
\end{tabular}

and severity of psychiatric symptoms (GAF-S). See supplementary Tables 3 and 4 for more details.

\section{Discussion}

\section{Main findings}

Our study is the largest to date to investigate demographic and clinical characteristics of people $\geq 65$ years admitted to a general adult PAU and the first to compare older adults with regard to PPH or $\mathrm{NPH}$ in this setting. Corresponding with our hypothesis we found that patients with NPH were more likely than patients with $\mathrm{PPH}$ to present with physical frailty, somatic comorbidity and functional and cognitive problems. Not least, the NPH group were more likely to have made a suicide attempt before admission.

Despite most guidelines recommending that older adults with recent presentation of mental illness should receive specialised psychogeriatric treatment, ${ }^{6-9}$ there are few studies that specifically investigate the characteristics of older adults with no previous psychiatric treatment history of any kind before their first psychiatric admission. In line with our aim to strengthen the empirical basis 
for how to organise old-age mental health services, our findings add important information about this severely ill group and highlight the multifactorial nature of the problems with which they present in a clinical setting.

\section{Suicidality}

There were no statistically significant differences between the NPH and $\mathrm{PPH}$ groups with regard to admission because of suicide risk. However, in the NPH and PPH groups combined, the proportion of patients with suicide-risk-related admissions (31.6\%) was much lower than that of the total patient cohort regardless of age from the same study (55\%). ${ }^{19}$ This might seem like a paradox considering the high suicide rates found in older age groups ${ }^{1}$ and might indicate that psychiatric services are currently not sufficiently reaching these patients. This hypothesis is further supported by the studies showing that although older adults who end their life have often been in contact with a primary physician shortly before death, somatic problems are usually the topic of the consultation and mental issues such as depression remain undetected. ${ }^{28}$ Moreover, relatively few have had recent contact with specialised psychiatric services. ${ }^{29}$ In other studies reporting on admissions of older adults because of suicide risk, the rates vary from $13.3 \%{ }^{30}$ to $48.1 \%{ }^{31}$ However, these studies were set in specialised psychogeriatric units with differing intake criteria, making comparison with our findings difficult. Further, we found that although the patients in the PPH group were more likely to report suicidal ideation at the time of admission, the patients in the NPH group were more likely to have made a suicide attempt, the latter finding being robust for sensitivity analyses controlling for differences in age and organic disorders. This finding might indicate a difference in the expression of suicidality between these two groups, with the PPH group possibly being more likely to verbalise their suicidal ideation and the NPH group being more likely to act on it, which may be important for clinical practice. Cognitive impairment, significantly more common in the NPH group, may complicate suicide risk assessment further.

\section{Diagnostic and pharmacological differences}

Organic disorders were diagnosed almost six times more often in the NPH group than in the PPH group. Two previous studies found an association between first admissions in psychiatry and organic psychiatric disorders (ICD-10) ${ }^{16}$ or organic brain syndrome (DSM-III-R). ${ }^{17}$ The latter also found that patients admitted to hospital with NPH were more likely to have a concurrent medical problem, corresponding with the HoNOS scores and diagnostic findings in the present study. While affective disorders was the most frequently diagnosed category in the PPH group, nearly a third of the NPH group were diagnosed with an affective episode, corresponding with previous studies showing that late-life depression is commonly encountered in first admissions of older adults in psychiatry. ${ }^{32,33}$ Depression is strongly associated with increased suicide risk in elders, ${ }^{18}$ further underlining the importance of detecting and treating the disorder in this age group. Focusing on the important subject of addiction, one tenth of the patients in the study had issues with substance misuse (mainly alcohol), highlighting the clinical importance of these issues in the elderly population, which has been emphasised by previous studies. ${ }^{34,35}$

The PPH group were prescribed a higher number of psychotropic drugs than the NPH group. However, the numbers in both groups point to a tendency to polypharmacy that is unfortunate given the high risk of adverse effects and interactions from these drugs especially in this age group. ${ }^{3}$ Of the NPH group, a substantially higher proportion were given antipsychotic drugs than were diagnosed with a psychotic disorder. This may illustrate some of the challenges when treating older adults with cognitive impairment experiencing psychotic symptoms and behavioural difficulties in whom non-pharmacological interventions have failed. While antipsychotics such as risperidone can have an alleviating effect on aggression and agitation in dementia, ${ }^{36}$ caution should be taken in this patient group because of the potentially life-threatening adverse effects ${ }^{3}$ and limited evidence of a clinically meaningful benefit. ${ }^{37}$

\section{Clinical and sociodemographic differences}

Although in the total cohort of older adults both gender distribution and mean age were similar to the findings in previous studies, ${ }^{32,33,38-40}$ the NPH group were significantly older than the $\mathrm{PPH}$ group and a higher proportion were men, the former being a novel finding. One of the very few previous studies that included a subsample of elderly patients with no prior contact with the mental healthcare system reported a similar gender distribution. ${ }^{17}$ Both age and gender differences may be relevant when reviewing the HoNOS and GAF scores. These indicate that the patients in the NPH group present with a more complex, severe and multifaceted symptomatology and more impaired functioning than the patients in the PPH group, including problems with aggressive or disruptive behaviour, physical illness and disability, cognition and with activities of daily living.

The NPH group being older is probably associated with the high degree of somatic comorbidity, dementia and other organic psychiatric disorders we identified in this group, which was in part confirmed by the analyses adjusting for age. The preponderance of organic and somatic disorders may again be associated with more behavioural difficulties, cognitive problems and a reduced level of functioning, as previously also shown in psychogeriatric populations assessed with HoNOS. ${ }^{41}$ Regarding gender, prior studies have found that men with advanced dementia are more assaultive than women, ${ }^{35,42}$ potentially causing them to be particularly difficult for caregivers to manage and increasing the likelihood of psychiatric admission. ${ }^{43}$ This could in part explain the disproportionate amount of male patients in the NPH group. However, the male preponderance in the NPH group was robust for the age and organic disorder sensitivity analyses. More aggressive behaviour may also in part explain the high rate of involuntary admissions in the NPH group. Furthermore, the decreased cognitive functioning in the NPH group may impair the capacity to consent to voluntary measures. The sensitivity analyses excluding organic disorders and controlling for age indicate that behavioural difficulties, cognitive problems and involuntary referral was in fact associated with age and a diagnosis of organic disorders.

Although the rates of patients in the NPH group who were married or widowed were comparable with that of the average elderly population in Norway, ${ }^{44}$ patients in the PPH group were more likely to be divorced or single and living alone at the time of admission. This could be a reflection of the social consequences experienced by many in the $\mathrm{PPH}$ group chronically struggling with serious mental illness, possibly decreasing the chance of a stable marriage or partner. ${ }^{45}$ These findings were strengthened by the fact that single and married status was robust for sensitivity analyses, indicating that the NPH group are more similar to the general elderly population irrespective of age. For patients with functional impairment, the lack of a supportive living partner might be relevant regarding the level of follow-up needed after the admission.

\section{Psychogeriatric transfer and guideline adherence}

Despite being the most common destination of transfer in the NPH group, psychogeriatric units actually received less than half of patients in the NPH group. This number might seem low, and could point to psychogeriatric capacity issues and/or indicate that 
current guidelines are not sufficiently adhered to. As demonstrated by the other findings of our study, it is highly likely that many of these patients have complicating assessment and treatment needs relating to somatic comorbidity, cognitive and functional impairment, which have a higher risk of going unmet at a general adult unit than at an old age psychiatric unit. ${ }^{12}$ The question needs to be raised whether general PAUs without any specific geriatric competence or facilitation are adequately suited to meet the needs of this frail patient group. Although most patients with a PPH were transferred from the PAU to general adult psychiatric units, one out of five were transferred to psychogeriatric units. We do not know the reason(s) for psychogeriatric transfer for these particular patients, however, it may be assumed that they were transferred to psychogeriatric units after individual assessment of need, even though their mental illness started before the age of 65 . This highlights the fact that while complex assessment and treatment needs were most frequently found in the NPH group, clearly many patients with a PPH also presented with such needs. Although a detailed evaluation of patient transfer practice and comparison of different psychogeriatric intake criteria was not the focus of this article, our findings call for further research into this area.

\section{Strengths and limitations}

Strengths of this study are the large number of patients and the complete, prospective recruitment of patients in a defined geographical area. The naturalistic setting that included $95 \%$ of all emergency admissions in the catchment area in the study period, combined with a universal free healthcare with (virtually) no competition from private healthcare facilities ensure high generalisability and representability. Demographic information, as well as the variables concerning clinical diagnoses and medications on discharge are robust and nearly complete. Moreover, data registration from hospital records was performed and controlled by well-trained research nurses.

Some limitations apply to the study: a majority of the data, including information on whether or not the patients had any PPH before the age of 65 , is restricted by the accuracy of the hospital records from which they were obtained. Our definition of $\mathrm{PPH}$, defined by contact with specialised psychiatric services or not, does not rule out that some patients in the NPH group may have experienced mental health problems at some point in their life that were not treated, treated a long time ago or was in primary care. The clinical ratings were administered by on-call psychiatric residents and reliability scoring was not conducted. There was some missing data for some of the variables, especially the HoNOS. The imputation of these variables should give more precise estimates, as we assume that relevant predictors were included in the conditional imputation model.

\section{Implications of our findings}

The present study shows that in patients of $\geq 65$ years admitted to a general adult PAU no previous contact with mental healthcare system is associated with more frequent concurrent problems relating to physical frailty, somatic comorbidity and functional and cognitive impairment, as well as higher rates of preadmission suicide attempts. Even though cognitive and somatic findings were associated with the NPH group being older and more frequently diagnosed with organic disorders, several characteristics of the NPH group were robust for age correction even after exclusion of patients with organic disorders. Still, the main aim was to investigate if a crude division of elderly patients with and without former psychiatric treatment captures a distinct clinically relevant subcohort, which we conclude that it did. As psychogeriatric units are superior to general adult psychiatric units at providing elderly patients with comprehensive medical and psychiatric work-up, ${ }^{11}$ as well as meeting the multi-faceted needs ${ }^{12}$ undoubtedly present in this patient group, our findings support the current recommendation of several psychogeriatric guidelines of assigning elderly patients to either geriatric or general psychiatry based on the age at onset of mental illness.

Subdividing patients to treatment in psychogeriatric services based on the age of mental illness presentation is a practical and unequivocal approach and may be especially clinically useful in a busy acute unit when triaging the needs of elderly psychiatric patients. As it was not within the scope of our study, we cannot offer a substantial evaluation of 'ageless' psychogeriatric intake criteria based on individual assessment of need; ${ }^{10}$ however, our findings clearly show that needs typically indicating psychogeriatric rather than general psychiatric treatment more commonly occur in elderly patients with onset of mental illness $>65$ years. In any case, our findings highlight the multifactorial problems of this severely ill patient group and call attention to the importance of any admitting facility being adequately suited to manage them. Future research in this field should focus on longitudinal data such as causes of death, suicide, re-admissions to hospital as well as somatic comorbidity and complications, further evaluating the current system treating the most ill elderly psychiatric patients. We will endeavour to investigate follow-up data of the present cohort in future publications.

Hallvard Lund-Heimark (D), MD, Research Department, Division of Psychiatry, Haukeland University Hospital, Norway: Eirik Kjelby, MD, Research Department, Division of Psychiatry, Haukeland University Hospital, Norway: Lars Mehlum, MD, PhD, National Centre for Suicide Research and Prevention, Institute of Clinical Medicine, University of Oslo, Norway; Rolf Gjestad, MD, PhD, Research Department, Division of Psychiatry; and Centre for Research and Education in Forensic Psychiatry, Haukeland University Hospital, Norway; Geir Selbæk, MD, PhD, Norwegian National Advisory Unit on Ageing and Health, Vestfold Hospital Trust, Norway; Institute for Clinical Medicine, Faculty of Medicine, University of Oslo; and Department of Geriatric Medicine, Oslo University Hospital, Norway; Rune Andreas Kroken, MD, PhD, Norment, Division of Psychiatry, Haukeland University Hospital, Norway; and Department of Clinical Medicine, University of Bergen, Norway; Erik Johnsen, MD, PhD, Norment, Division of Psychiatry, Haukeland University Hospital, Norway; and Department of Clinical Medicine, University of Bergen, Norway; Ketil Joachim Oedegaard, MD, PhD, Norment, Division of Psychiatry, Haukeland University Hospital, Norway; and Department of Clinical Medicine, University of Bergen, Norway; Liv S. Mellesdal, PhD, Research Department, Division of Psychiatry, Haukeland University Hospital, Norway

Correspondence: Hallvard Lund-Heimark. Email: htlu@helse-bergen.no

First received 12 Nov 2019, final revision 24 Apr 2020, accepted 14 May 2020

\section{Supplementary material}

Supplementary material is available online at http://doi.org/10.1192/bjo.2020.45.

\section{Data availability}

The data are not publicly available due to restrictions given by the Committee for Medical Research.

\section{Acknowledgements}

The authors thank Jill Bjarke, RN, Geirr Fitje, BBA, Petter Jacobsen, RN, Linn Aaberg, RN, Anne Synnøve Thomassen, RN and Marianne Langeland, RN for their contribution to the high quality of the data.

\section{Author contributions}

H.L.-H. drafted the manuscript, participated in data analysis and interpretation of data. E.K. helped draft the manuscript and made substantial contributions to project design and the anaIysis and interpretation of the data. L.M. helped draft the manuscript, provided expertise in the field of suicidology and participated in project design and interpretation of data. R.G. helped draft the manuscript and supervised data analysis and interpretation. G.S. helped draft the manuscript and provided expertise in the field of geriatric psychiatry. R.A.K. helped draft the manuscript and contributed to project design and interpretation of data. E.J. helped draft the manuscript and contributed to project design and interpretation of data. K.J.O. was a principal investigator during data collection and helped draft the manuscript. L.S.M. helped draft the manuscript and made substantial contributions to project design, data collection, data analysis and interpretation. 


\section{Funding}

This project was supported by a research grant from the Western Norway Regional Health Authority.

\section{Declaration of interest}

None.

ICMJE forms are in the supplementary material, available online at https://doi.org/10.1192/ bjo.2020.45.

\section{References}

1 Värnik P. Suicide in the world. Int J Environ Res Public Health 2012; 9: 760.

2 Skoog I. Psychiatric disorders in the elderly. Can J Psychiat 2011; 56: 387-97.

3 O'Mahony D, O'Sullivan D, Byrne S, O'Connor MN, Ryan C, Gallagher P. STOPP/ START criteria for potentially inappropriate prescribing in older people: version 2. Age Ageing 2015; 44: 213-8.

4 Roth M. Mental health problems of aging and the aged. Bull World Health Organ 1959; 21: 527-61.

5 Draper B. The elderly admitted to a general hospital psychiatry ward. Aust NZJ Psychiatry 1994; 28: 288-97.

6 American Association for Geriatric Psychiatry. AAGP Position Statement: The Clinical Roles and Functions of the Geriatric Psychiatrist. American Association for Geriatric Psychiatry, 1997 (https://www.aagponline.org/index.php?src= news\&submenu=Tools_Resources\&srctype=detail\&category=Position\%20State ment\&refno=44).

7 The Royal Australian \& New Zealand College of Psychiatrists. Position Statement 22. Psychiatry Services for Older People. Royal Australian \& New Zealand College of Psychiatrists, 2015.

8 Legeforeningen. Plandokument for Norsk Alderspsykiatri 2011-2020. [The Norwegian Document of Geriatric Psychiatry 2011-2020.] Norwegian National Advisory Unit on Ageing and Health, Norwegian Psychiatric Association, 2010 (https://www.legeforeningen.no/contentassets/bb7d953b9ad54f8caa57c93107 44e770/plandokument.pdf).

9 The Canadian Coalition for Seniors' Mental Health. National Guidelines for Seniors' Mental Health. Can J Geriatr 2006; 9 (Suppl 2): 36-71.

10 Faculty of the Psychiatry of Old Age, Royal College of Psychiatrists. Criteria for Old Age Psychiatry Services in the UK. Royal College of Psychiatrists, 2015

11 Yazgan IC, Greenwald BS, Kremen NJ, Strach J, Kramer-Ginsberg E. Geriatric psychiatry versus general psychiatry inpatient treatment of the elderly. Am J Psychiatry 2004; 161: 352-5.

12 Abdul-Hamid WK, Lewis-Cole K, Holloway F, Silverman AM. Comparision of how old age psychiatry and general adult psychiatry services meet the needs of elderly people with functional mental illness: cross-sectional survey. $\mathrm{Br} J$ Psychiatry 2015; 207: 440-3.

13 Warner JP. Old age psychiatry in the modern age. Br J Psychiatry 2015; 207 : 375-6.

14 National Institute for Health and Care Excellence. Older People: Independence and Mental Wellbeing. NICE Guideline (NG32). NICE, 2015.

15 Freyne A, Wrigley M. Acute inpatient admissions in a community oriented old age psychiatry service. Ir J Psychol Med 2014; 14: 4-7.

16 Furukawa Y, Odawara T, Yamada Y, Fujita J, Hirayasu Y. Features of elderly patients admitted to a general hospital psychiatric unit. Psychogeriatrics 2006; 6: 55-9.

17 Shulman RW, Marton P, Fisher A, Cohen C. Characteristics of psychogeriatric patient visits to a general hospital emergency room. Can J Psychiatry 1996; 41: $175-80$

18 Erlangsen A, Zarit SH, Tu X, Conwell Y. Suicide among older psychiatric inpatients: an evidence-based study of a high-risk group. Am J Geriatr Psychiatry 2006; 14: 734-41.

19 Mellesdal L, Kroken RA, Lutro O, Wentzel-Larsen T, Kjelby E, Oedegaard KJ, et al. Self-harm induced somatic admission after discharge from psychiatric hospital - a prospective cohort study. Eur Psychiatry 2014; 29: 246-52.

20 Mellesdal L, Mehlum L, Wentzel-Larsen T, Kroken RA, Jørgensen HA. Suicide risk and acute psychiatric readmissions: a prospective cohort study. Psychiatr Serv 2010; 61: 25-31.

21 Mueser $\mathrm{K}$, Drake R, Clark R, McHugo G. Mercer-McFadden C. Toolkit for Evaluating Substance Abuse in Persons with Severe Mental Illness. Evaluation Center, Human Services Research Institute, 1995
22 Wing JK, Beevor AS, Curtis RH, Park SB, Hadden S, Burns A. Health of the Nation Outcome Scales (HoNOS). Research and development. Br J Psychiatry 1998; 172: $11-8$.

23 Pedersen G, Karterud S. The symptom and function dimensions of the Global Assessment of Functioning (GAF) scale. Compr Psychiatry 2012; 53: 292-8.

24 Hall RCW. Global Assessment of Functioning. Psychosomatics 1995; 36: 267-75.

25 World Health Organization. ICD-10: International Statistical Classification of Diseases and Related Health Problems: tenth revision, 2nd ed. WHO, 2004 (https://apps.who.int/iris/handle/10665/42980).

26 Schafer JL, Graham JW. Missing data: our view of the state of the art. Psychol Methods 2002; 7: 147-77.

27 Enders CK. Applied Missing Data Analysis. The Guilford Press, 2010

28 Conwell Y, Van Orden K, Caine ED. Suicide in older adults. Psychiatr Clin North Am 2011; 34: 451-68

29 Walby FA, Myhre MØ, Kildahl AT. 1910 Døde Pasienter: Selvmord i Psykisk Helsevern og Tverrfaglig Spesialisert Rusbehandling 2008 til 2015 - en Nasjonal Registerstudie. Nasjonalt Kartleggingssystem for Selvmord I Psykisk Helsevern Og Tverrfaglig Spesialisert Rusbehandling. Hentet fra. [1910 dead patients. Suicide within one year after contact with mental health- and substance misuse services 2008-2015 - a national registry study from Norway.] The Norwegian National Centre for Suicide Research and Prevention, 2018 (https://www.med.uio.no/klinmed/forskning/sentre/nssf/kartleggingssystemet/ dokumenter/rapporter/nssf_kartleggingssystemet_rapport_web_korrigert_p.pdf).

30 Wetterling T, Gutzmann H, Haupt K. Reasons for referral to a gerontopsychiatric department. Nervenarzt 2008; 79: 340-7.

31 Carpar E, McCarthy G, Adamis D, Donmezler G, Cesur E, Fistikci N. Sociodemographic characteristics and factors associated with hospitalization in psychiatry of old age patients: an international comparison between Ireland and Turkey. Aging Clin Exp Res 2017; 30: 651-6.

32 Choi S, Rozario P, Morrow-Howell N, Proctor E. Elders with first psychiatric hospitalization for depression. Int J Geriatr Psychiatry 2009; 24: 33-40.

33 Burke WJ, Roccaforte WH, Wengel SP. Characteristics of elderly patients admitted for the first time to a psychiatric facility. 1988; 1: 159-62.

34 Aich $\mathrm{T}$, Dhungana M, Muthuswamy R. Pattern of neuropsychiatric illnesses in older age group population: An inpatient study report from Nepal. Indian J Psychiatry 2012; 54: 23-31.

35 Tueth MJ, Zuberi P. Life-threatening psychiatric emergencies in the elderly: overview. J Geriatr Psychiatry Neurol 1999; 12: 60-6.

36 Devanand DP, Mintzer J, Schultz SK, Andrews HF, Sultzer DL, de la Pena D, et al. Relapse risk after discontinuation of risperidone in Alzheimer's disease. N Engl J Med 2012; 367: 1497-507.

37 Corbett A, Burns A, Ballard C. Don't use antipsychotics routinely to treat agitation and aggression in people with dementia. BMJ 2014; 349: g6420.

38 Moss F, Wilson B, Harrigan S, Ames D. Psychiatric diagnoses, outcomes and lengths of stay of patients admitted to an acute psychogeriatric unit. Int Geriatr Psychiatry 1995; 10: 849-54.

39 Brandao D, Freitas A, Paul C, Ribeiro O. Psychiatric disorders as main discharge diagnosis by the Portuguese oldest old from 2000 to 2014: exploring national acute inpatient admissions. Int Psychogeriatr 2018; 30: 685-94.

40 chung W, Oh SM, Suh T, Lee YM, Oh BH, Yoon CW. Determinants of length of stay for psychiatric inpatients: analysis of a national database covering the entire Korean elderly population. Health Policy 2010; 94: 120-8.

41 Cheung G, Strachan J. Routine 'Health of the Nation Outcome Scales for elderly people' (HoNOS65+) collection in an acute psychogeriatric inpatient unit in New Zealand. N Z Med J 2007; 120: U2660.

42 Savage T. Relationship between assault frequency and length of hospitalization in older patients with dementia-determining the maximum benefit of inpatient treatment. J Gerontol Nurs 2007; 33: 13-20.

43 Stevenson GS, Khan MA, Perumal N. A psychiatric intensive care unit for older adults: an interval comparison of admissions. Int Psychogeriatr 2009; 21: $278-85$.

44 Mørk E. Seniorer i Norge 2010. [Elderly people in Norway 2010.]. Statistisk Sentralbyrå, 2011.

45 Agerbo E, Byrne M, Eaton WW, Mortensen PB. Marital and labor market status in the long run in schizophrenia. Arch Gen Psychiatry 2004; 61: 28-33. 